\title{
Rui Barbosa e as letras jurídicas.
}

\author{
Ataliba Nogueira \\ Professor emérito da Faculdade de Direito da \\ Universidade de São Paulo.
}

\section{I}

A partir da independência surgem entre nós grandes e notáveis juristas, enriquecendo as letras nacionais com obras valiosas nos vários campos da ciência do direito.

No parlamento do império e no congresso nacional da república, a apresentação dos projetos de lei e a sua tramitação regimental eram acompanhados de justificações e pareceres reveladores da cultura jurídica dos representantes.

No conselho de estado na monarquia e nos mais altos tribunais em ambos os regimes, a exposição do direito esbatia-se do esmero com que eram dadas as opiniões. Igualmente bem fundamentados os votos e acórdãos em que se cristalizava o juízo a respeito das questões propostas.

Incontestavelmente dois focos de irradição do cultivo destas letras foram as Faculdades de Direito de São Paulo e de Olinda, esta mais tarde transferida para o Recife. Seu nome legal, Academia de Direito, parecia atribuir-lhes de preferência ao ensino profissional, a dedicação às lucubrações da inteligência no campo da norma jurídica. Chega a esta conclusão todo aquele que ler a história destas Faculdades, escrita, respectivamente, pelos seus professores, Spencer Vampré e Clóvis Bevilaqua.

De outro lado ,as revistas de jurisprudência consagravam páginas numerosas à doutrina e à crítica dos julgados. 
Enfim, o direito no Brasil, na primeira centúria a partir da independência, conta com juristas, professores, magistrados e advogados notabilíssimos, cuja relação, mesmo incompleta e de cuidadosa seleção, daria para encher uma dezena de páginas.

Consideremos, pois, como foi gigantesca a figura de Rui Barbosa para se salientar nessa teoria de homens de alto valor. Já seria muito atingir o nivel de quantos se colocaram na mais saliente posição. Imagine-se, agora, ser considerado o primeiro dentre os nossos juristas máximos, sem em nada se buscar diminuir qualquer dos demais.

Além disto, cada qual dos nossos cultores do direito se destinguia num ou em alguns dos ramos jurídicos, ao passo que Ru Barbosa se notabilizou em todos eles.

Pondere-se também que se não circunscrevia a esta ou àquela profissão, mas quase concomitantemente foi politico, advogado, jornalista, parlamentar, diplomata, escritor, conferencista, filólogo, polemista, internacionalista, e ainda exerceu outras atividades. Acrescente-se: notável estadista.

Realmente foi genial.

Afirma-o o consenso de todos nós ao examinarmos a vida e os feitos dos nossos grandes homens, ao ponderarmos como seria possível armazenar tanto saber, conhecendo o volume enorme de dificuldades que teve de debelar.

Inteligência portentosa, memória bem exercitada para reter quanto aprendia, diligência e trabalho diário, sem descanso desde a madrugada até o pôr do sol. Sacrificou a vida debruçado sobre os livros, em leitura e estudo proveitoso, de caneta na mão a fixar no papel aquilo que talvez um dia lhe fosse de proveito.

Teve sólida formação humanista adquirida no Ginásio baiano e na convivência com seu pai; estudo sério nas duas Academias de Direito que freqüentou; avidez de saber e curiosidade ao abeberar-se na fonte dos livros da vasta biblioteca formada a pouco e pouco. Esteve sempre a par 
das últimas novidades literárias, em qualquer genero, encomendadas na Europa e América do Norte.

A prova têmo-la de modo irrefragável principalmente nos artigos de imprensa e nos debates do senado. Revelava aqui e ali como conhecia o que fosse mais novo na doutrina e nos fatos trazidos à discussão. Prova-o ainda o seu próprio espírito versátil. O primeiro significado de versátil é mudavel. Não lhe causava espécie aceitar as idéias novas, as doutrinas que surgiam, desde que destruissem as barreiras do seu conhecimento no assunto, abalassem as razões da sua convicção ou se firmassem em fatos novos ou novamente descobertos.

Tal era o poder da verdade, cujo culto, este sim, foi invariável em toda a sua vida, mesmo que lhe custasse dissabores, sofrimentos, injustiças; curtisse embora desassossego, tristeza, perseguição, exílio.

A sua força moral perante os doutos, fossem amigos ou inimigos, provinha da leadade em aceitar a verảade e por ela pugnar.

$\mathrm{O}$ seu culto à verdade esteve sempre entrelaçado ao amor à justiça. A pena, a palavra, o saber jurídico, o seu prestígio estiveram, sem desfalecimento, ao serviço dos oprimidos, dos fraudados, dos perseguidos pelos poderosos do dia. Vários destes opressores, passado algum tempo, decaídos das posições de mando pelas vicissitudes da politica, ao sofrerem também a injustiça, foram buscar o integro Rui para defendê-los.

o mais fecundo escritor da língua portuguesa, depois da sua morte teve aumentada consideravelmente a divulgação dos seus trabalhos literários pela diligência da Casa de Rui Barbosa, instituição pública destinada a reunir todos os seus escritos dispersos pelos jornais, pelos Anais do Senado, pelos autos forenses ou os pareceres que ficaram em poder dos consulentes.

Não só os discursos de paraninfo no Colégio Anchieta e a Oração aos moços na Faculdade de Direito de São 
Paulo, mas também os seus discursos políticos e artigos nos jornais são pregações de apóstolo. Valia-se de todas as circunstâncias para orientar os brasileiros, traçar-lhes o caminho da justiça, apontar-lhes as virtudes cívicas, clamar pela democracia, a sinceridade na representação política, a luta sem quartel à ditadura.

Tal pregação, como dissemos, não foi apenas nas duas campanhas eleitorais para a presidência da república, a civilista de 1909-10 e a de 1919, pois era o mote de todos os seus discursos.

Grande parte dos admiradores o tinham como ídolo, como divindade terrestre. É certo que muitas vezes as suas palavras foram proféticas e os seus vaticínios se realizaram. Haja vista as plataformas com que se apresentou candidato, nas duas vezes em que aceitou a disputa para presidente da república.

Em 17 de dezembro de 1909 profere, na Faculdade de Direito de São Paulo, o notável discurso sobre A Justiça. Em 1919, declara haver abandonado o liberalismo econômico e propugna para o Brasil extenso programa de realizações sociais. Programa bem avançado para que, esteiado na justiça, o Brasil atinja a paz social, sem luta de classes. Diz com todas as letras que é pela democracia social.

O ideal a que se referiu sempre em vários discursos, define-se agora de modo claro, em proposições concretas, de atualização difícil mas necessária, pois é imposição da justiça. E é pelo direito que se há de realizar a justiça.

Eis o apóstolo da lei, que é o direito, mas da lei justa, pois o direito, muitas, muitíssimas vezes tem sido injusto.

Assim, não era conservador, pretendia reformas radicais, da mesma maneira que aos vinte anos de idade, com os seus colegas do curso jurídico em São Paulo, pretendia acabar com o direito de propriedade sobre os escravos, direito iníquo, firmado na injustiça. Consagravam-no as leis, impunham-no sob coação os tribunais. 
Referimos de maneira genérica a contribuiçãc do grande brasileiro às letras jurídicas pátrias.

Já agora pretendemos salientar a sua colaboração em dois monumentos jurídicos brasileiros: a constituição federal de 1891 e o código civil de 1916.

Ambos revelam o seu alto espírito crítico, o denodo com que combatia pelas suas idéias, terçando armas com os nossos maiores políticos e cultores do direito. Denunciam a sua cultura enciclopédica, a lógica no desenvolvimento do raciocínio, a elegância da palavra oral e escrita, a clareza da exposição.

Para elaborar o projeto constitucional, o governo provisório nomeou uma comissão em 3 de dezembro de 1889. 0 resultado do seu trabalho foi submetido ao ministério, que o discutiu artigo por artigo e refundiu o projeto, sendo Rur Barbosa, um dos ministros, o principal redator do trabalho que se realizou em sua casa.

Assim, o projeto definitivo aprovado por decreto do governo, embora resultado da referida discussão, é da sua lavra e letra.

O professor Americo Jacobina Lacombe, ilustre historiador e presidente da Fundação da Casa de Rui Barbosa, compulsando os manuscritos ali guardados, afirma que 74 dos 90 artigos da constituição provêm do projeto definitivo decretado pelo governo. Resulta daí haver sido de Rur a maior contribuição ao texto definitivo da constituição. Aliás o mesmo zeloso historiador publicou todos os documentos referentes ao assunto, em volume das Obras completas, tarefa principal da Casa de Rui Barbosa.

$\mathrm{Na}$ elaboração do projeto de constituição, como depois na sua discussão em Assembléia constituinte, RuI, que sempre fora e continuaria a ser o maior defensor dos direitos humanos e das liberdades individuais, reproduziu 
também o que constava do decreto de sua lavra, estabelecendo a separação da igreja do estado. Não só estabelecia a separação entre a igreja e o estado, no que estava certo, mas reproduziu outros dispositivos do decreto, evidentemente antiliberais, como a legislação sobre os bens de mãomorta, a interdição de novos conventos e a exclusão da Companhia de Jesus de todo o território nacional.

A defesa dos assim violentamente esbulhados dos seus direitos coube aos positivistas, os discípulos de Augusto Comte e Teixeira Mendes. Representados no governo (aqui foi Demetrio Ribeiro que repudiou aquelas medidas antiliberais) e na Constituinte, eles e os representantes católicos conseguiram expungir a constituição daquela mancha.

Ror nunca foi irreligioso, mas na verdade só se voltou integralmente para a sua fé católica depois do exílio na Inglaterra. Mostrou-se surpreso por tal assunto interessar a ilustre membro do governo inglês, lord Balfour, que acabava de publicar o seu livro sobre Os fundamentos da fé. Analisa-o nas Cartas de Inglaterra. Algum tempo depois lord Balfour passa a chefe do governo inglês.

Daí por diante surge outro Ruı, o das Palavras à juventude, o dos discursos políticos em que salienta sempre a formação católica do Brasil, o da apologia eucarística no seu jubileu político, o da Oração aos moços, maravilha de afirmações religiosas. Assistido por frei Celso Dreiling, dos franciscanos de Petrópolis, a quem conhecemos pessoalmente, morre como bom cristão a $10^{\circ}$ de março de 1923, data que hoje comemoramos, havendo recebido todos os sacramentos da Igreja.

Voltemos à constituinte de 1890. Ele a é a grande autoridade de jurista e de político. Partidário convicto e desfraldador da bandeira da federação no Brasil no último ano da monarquia, teve então atitude firme ao combater o separatismo ou enfraquecimento dos laços nacionais, a 
pretexto de federação. Era espírito perfeitamente equilibrado.

Desde a constituinte do império, em 1823, jamais foi posto de lado o desejo popular pela federação, que, aliás, provinha históricamente da organização das capitanias hereditárias. Era arraigado no povo brasileiro.

Em nosso curso, na Faculdade de Direito, expusemos minudentemente o assunto. Rũ não foi tão longe quanto nós e não era preciso naquele momento histórico, em que batalhou e obteve a vitória da sua campanha eficiente em artigos do Diário de Notícias. Bastava-lhe invocar os argumentos extraídos do momento histórico por que passava o Brasil.

E por isto que podemos afirmar ser a idéia da federação no Brasil tanto brasileira quanto americana.

Os fatos históricos correram por assim dizer paralelos, no Brasil e na América do Norte, desde o início da colônia lá e aqui.

Rur encontrou já em fórmula jurídica aquilo que entre nós devia ser realizado em conseqüencia da tradição e anseio popular.

Rui não no fez de afogadilho, ao aderir à república poucos dias antes de 15 de novembro. Já bem antes, quando em maio o partido liberal elaborou o programa de governo para dentro em breve voltar ao poder, apresentou aos seus correligionários um plano para a organização federativa do estado no Brasil, mantida inteiramente a forma monárquica de governo e atingido em parte só o parlamentarismo.

Subscrevem-no vários ilustres companheiros de partido, mas é rejeitado.

Chegando agora ao poder com o convite dos republicanos para realizar o seu plano de federação, valeu-se da construção constitucional elaborada na América do Norte pela vida política dos primeiros anos das treze coIônias independentes. 
Extraiu do direito público americano a fórmula jurídica da autonomia recíproca entre os poderes centrais e regionais, sob a égide da constituição, que é como definimos na cátedra a federação.

Repetimos: a federação era fenômeno histórico tanto brasileiro quanto americano, o primeiro que a realizasse havia de dar-lhe a forma jurídica. Precederam-nos os norte-americanos; nós não poderíamos inventar nova fórmula. Ou é federação ou não é. Se é, são sempre as mesmas características, aliás poucas, segundo a nossa definição.

Uma vez conservados os elementos integrantes da definição, tudo o mais necessariamente há de variar, sendo como são diferentes as condições do meio, a história, a política, as tradições deste ou daquele estado.

Existem atualmente no mundo trinta e duas federações. São federações porque preenchem os requisitos indispensáveis à forma federativa e no entanto cada qual é constituída de acordo com as condições do seu meio, da sua hisłória, das suas outras peculiaridades.

Rư teve o grande mérito de nos dar a organização jurídica fundamental baseada na federação. Combateu os excessos de muitos dos constituintes de 1890; logo depois propôs reformas à constituição de $1891 \mathrm{em}$ vários pontos a fim de adequar melhor o texto legal à realidade. Não é eterno o direito positivo; muda como muda a línguagem, como mudam os usos e costumes, a moda, a arte, a técnica, as formas políticas e econômicas. Só não muda o direito natural, que assim mesmo se reduz ao conceito de justiça e nada mais.

A chave da constituição de 1891, se assim podemos dizer, reside na distribuição de competências entre os poderes da União e os dos estados; nas atribuições exclusivas do poder legislativo, sem qualquer concorrência; na colocação do presidente da república como chefe único do poder executivo; na revisão judicial dos atos legislativos e administrativos; na representação política do povo 
e dos estados; no enunciado e nas garantias dos direitos individuais e entre estas a principal, o habeas corpus.

Rur foi o mestre maior e o mais denodado doutrinador dos preceitos constitucionais. Na realidade teve que ensiná-los à magistratura, ao presidente da república e aos membros do congresso nacional. E agir perante eles com intrepidez, destemor e bravura.

Nesta luta sagrou-se o maior advogado do Brasil, exemplo e modelo para quantos se dedicam a tão nobre profissão, sendo que nenhum mais do que ele dignificou a sua classe. Principalmente no pretório defendeu os perseguidos, os injustiçados, os oprimidos. E o fez com tal competência e desassombro que até hoje os verdadeiros advogados lhe seguem a traça,

Não têm razão os que se referiram ao idealismo $d a$ constituição de 1891 buscando com este eufemismo amesquinhá-la em face da realidade nacional. Carecia ela, sem dúvida, de duas sortes de medidas: a prática cotidiana e sincera dos seus preceitos e a reforma ou emenda de vários deles. Tudo isto se contém na ação apostolar do mestre, que não foi atendido. A revolução preferiu pôr por terra aquele monumento jurídico. Mas, para glória do seu autor principal, os arquivos dos tribunais, os anais do congresso nacional e as suas plataformas de governo constituem o libelo contra os demolidores da ordenação jurídica constitucional datada de 1891.

E de lamentar que entre eles se encontrassem até fanáticos adoradores de Rur, que se encastelaram no liberalismo e no individualismo, sem enxergar que ele, o mestre, sem nunca deixar de proclamar a inviolabilidade das liberdades públicas e individuais, afastou de si os princípios do liberalismo e enveredou resolutamente pelos direitos sociais. Preferiram ficar com o Rur da primeira posição, em questões que não admitem opção e o próprio Rur justifica com lógica férrea o seu abandono. 
Jamais pudemos compreender tal atitude de ruistas que se colocam acima de RuI e recordamos os seus primeiros discursos, ainda acadêmico de direito, quando todos lhe admiravam o talento, a oratória, o arrojo, mas não aceitavam a sua idéia de abolir-se o direito de propriedade dos escravos!

\section{III}

Passemos a recordar os trabalhos de Rú BARBosa na elaboração do código civil.

Afirma-se que na codificação do nosso direito civil, quando se esperava do seu saber e experiência eficiente colaboração, tanto mais que tinha assento no congresso nacional, limitou-se Rù à tarefa de mero filólogo e defensor da linguagem.

Da complexidade dos fatos parece-lhes que a sua contribuição não foi além.

Dizem, de outro lado, que ficou enciumado porque o presidente Campos Sales não o convidou, a ele, para elaborar o código e aceitou a indicação, feita pelo ministro Epitácio Pessoa, do professor Clóvis Bevilaqua, ainda pouco conhecido.

Dizem, por último, que Rur se desinteressara de colaborar no estudo jurídico do código porque não quis abandonar a sua vida cheia de trabalhos os mais diversos: político, advogado, jurisconsulto, parlamentar, jornalista, membro da Academia Brasileira de Letras.

O convite a Clovis é de janeiro de 1899. Em 14 e 15 de março, em artigos no jornal A Imprensa, Rur atacou o governo pela "vaidade malsã" de pretender sancionar a lei dentro no seu quadrienio. E mostrava a necessidade do labor de tal ordenação ser lenta, cuidadosa, atenta, para que afinal resultasse na ereção de notável monumento jurídico, digno do Brasil. Queria um código que não envelhecesse depressa. 
Ao cabo de oito meses Clovis Bevilaqua entregou o seu projeto. Sob a presidência do ministro da Justiça, Epitacio Pessoa, uma comissão procede à sua revisão e em novembro de 1900 a câmara dos deputados recebe o projeto revisto.

Nesta casa do legislativo, uma comissão especial de deputados examina-o detidamente, modifica-o e transforma-o em projeto da câmara.

Em março de 1902 o projeto está no senado. Ruı é escolhido para presidente da comissão especial.

Em 3 de abril de 1902, ou seja uma semana depois de constituída a comissão do senado (e não em três dias, consoante assevera Clóvis Bevilaqua), Rui entrega o seu longo parecer, em que refunde quase todos os artigos, "muitos dos quais com apostilhas (somam ao todo 531), quer quanto à linguagem, quer quanto à técnica jurídica."

"Essa mole ingente de saber profundo e rude crítica filológica", escreve CLóvis, "provocou verdadeiro assombro admirativo."

Rư não poderia produzir o seu parecer no exíguo prazo de tres dias, como assevera o culta autor do projeto, nem numa semana como resulta da contagem dos dias em que os papéis permaneceram em seu poder.

O certo é que Rui acompanhou o andamento do projeto, desde que saiu das mãos de Clóvis, em outubro de 1899, havia mais de dois anos. Tomou conhecimento dos trabalhos da comissão nomeada pelo governo, da comissão da câmara dos deputados e do resultado da tramitação naquela casa do congresso.

Rui, que escrevera em A Imprensa e declarara da tribuna do senado que o curso da elaboração do código havia de ser lento, sem qualquer açodamento, quis demonstrar que por ele não seria embaraçado o projeto no senado. Dai afirmar ao presidente da casa que entregava 
o seu longo relatório ao cabo de poucos dias do recebimento da incumbência.

Não quis dizer que escrevera em tão poucos dias quinhentas páginas cheias de erudição.

Aos críticos deste parecer, respondeu Rui na famosa Réplica, publicada no último dia do mesmo ano de 1902.

Rur cultivava os estudos de linguagem desde os bancos do Colégio baiano, onde aprendeu com o seu mestre CarNEIRo Ribeiro a recolher ordenadamente todas as notas da leitura dos autores clássicos. Armazenou assim o acervo enorme de ensinamentos que ia colhendo há mais de quarenta anos. $\mathrm{E}$ aprimorou o estilo, imbuindo-se do gênio da língua portuguesa.

A sua assim tão larga contribuição, se foi essencialmente de linguagem e filologia, não deixou de ser igualmente jurídica, pois a linguagem é o primeiro instrumento do direito. Entra de cheio no rude trabalho da elaboração do direito, como também na interpretação e aplicação da lei.

Note-se ainda que Rur se não limitou a esta faina, mas ainda corrigio e aperfeiçoou a técnica jurídica do projeto da câmara.

Nestes dois sentidos são as respostas de seu antigo mestre Carneiro Ribeiro e de Clovis Bevilaqua, notável autor do projeto.

A imprensa e os meios cultos do Brasil continuavam a reclamar que o código fosse discutido e votado o quanto antes.

Agastado, renuncia à comissão. Recusado o pedido, escreve o seu Parecer Sobre a Parte Geral, sem ninguém suspeitar, pois guaraou sigilo. Lê em caráter reservado na comissão especial, em abril de 1905, aquilo que seria apenas o esboço do seu parecer e não propriamente o parecer.

Tal esboço não foi dado à publicidade e permaneceu inédito durante quarenta anos no arquivo do relator. Men- 
ciona-o e analisa-o pela primeira vez San Tiago Dantas, em 1949. Ignora-o o laborioso Fernando Nery na sua obra Rui Barbosa e o código civil, de quase seiscentas páginas. Limitou-se aos trabalhos sobre a discussão da forma literária.

Rư não podia fazer mais, em face da sua vida política e profissional, já como advogado de renome, já como jornalista, porque tais atividades principais enchiam os seus dias, ocupavam o seu tempo, da madrugada à noite, sem quartel.

No período de discussão do código civil, ocorreram a sucessão presidencial de Campos Sales, de Afonso Pena e do marechal Hermes da Fonseca, com as naturais lutas políticas em que ele era das figuras principais; a embaixada em Haya; a campanha eleitoral em que se empenhou para a presidência da república, conhecida como campanha civilista e o seu consectário, a oposição no quadriênio agitado do marechal Hermes.

Onde buscar tempo para o trabalho sereno do código civil, que martelava sempre que devia ser muito minucioso e sem pressa?

Tudo quanto fez no mencionado período constitui mole imensa, nem sequer igualada pelos mais operosos dentre os seus contemporâneos.

O parecer a que nos referimos, além de versar sobre algumas poucas partes do projeto, era também fragmentário. Por isto não quis entregar à comissão e conservou inédito. Mesmo assim, mostra logo que partiu de um mestre. Realmente é apenas indicio do que faria, se o tempo lho permitisse.

t interessante verificar, neste esboco, como RuI faz justiça a Clovis Bevilaqua, elogiando-o e, mais de uma vez, restaurando a redação de artigos da lavra do ilustre cearense, professor do Recife, emendada pelo projeto da camara dos deputados.

Quem lê hoje o esboço do parecer de Rur se impressiona não apenas com o rigor juridico com que trata os 
institutos de direito, mas ainda com a visão do futuro, com novas instituições que só cinqüenta anos depois haviam de surgir entre nós. Por exemplo, as fundações de direito público, rejeitadas em nosso meio até bem poucos anos atrás. Escreve Rur: "Nem sempre a personificação jurídica nos entes de direito público se alia, política ou administrativamente, a uma jurisdição territorial." $\mathrm{E}$ mais adiante: "O que releva é verificar se a instituição funciona, de algum modo, por uma delegação de poderes públicos ou se limita a ser um conjunto de forças individuais associadas." Importa que seja "um modo de ação da autoridade pública."

Achamos curioso que RuI, renovando sempre seus argumentos contrários à urgência com que se pretendia elaborar a codificação, escrevesse este período, que ousamos repetir hoje aos ilustres juristas que buscam introduzir o computador eletrônico no âmbito da justiça: "Miraculoso talismã de exterminar incertezas, fixar o direito, automatizar a jurisprudência, acabar com as variações dos tribunais, estabelecer no reino da justiça a infalibilidade mecanica das aplicações, a unidade geral dos arestos, sonho fútil que daria matéria a curioso capítulo sobre as superstições da publicidade em nossa terra." São palavras de 1911, data em que se não podia suspeitar da invenção dos computadores, mas se emprestava à idéia de código as vantagens miríficas que menciona.

Comemoramos a morte, faz cinqüenta anos, de um dos maiores brasileiros.

A sua atividade multiforme, a sua inteligência portentosa, o número considerável dos seus trabalhos impressos, a segurança dos seus conceitos, a linha moral do seu agir, tudo nos leva a recordar as suas páginas, a pensar quanto disse e escreveu. Não só o jurista, mas todos os brasileiros devem conhecer a evolução do seu pensamento e as passagens marcantes da sua vida. Além do mais, como RuI, devemos amar o Brasil e contribuir para o bem do nosso povo. 